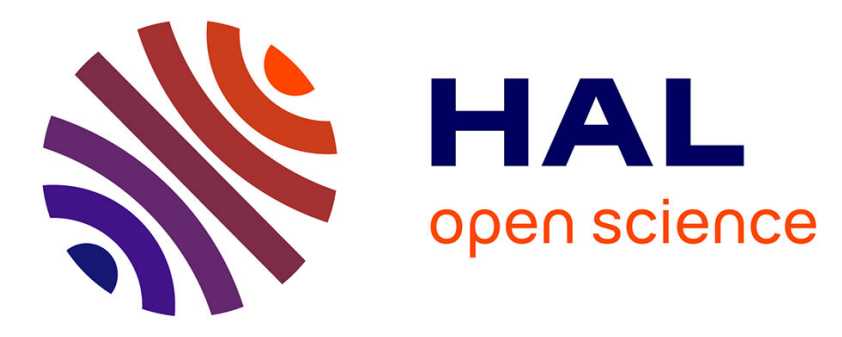

\title{
Food properties influence grasping strategies in strepsirrhines
}

Louise R Peckre, Anne-Claire Fabre, Julien Hambuckers, Christine E Wall, Lluís Socias-Martínez, Emmanuelle Pouydebat

\section{- To cite this version:}

Louise R Peckre, Anne-Claire Fabre, Julien Hambuckers, Christine E Wall, Lluís Socias-Martínez, et al.. Food properties influence grasping strategies in strepsirrhines. Biological Journal of the Linnean Society, 2019, 127 (3), pp.583-597. 10.1093/biolinnean/bly215 . hal-03031397

\section{HAL Id: hal-03031397 https://hal.science/hal-03031397}

Submitted on 30 Nov 2020

HAL is a multi-disciplinary open access archive for the deposit and dissemination of scientific research documents, whether they are published or not. The documents may come from teaching and research institutions in France or abroad, or from public or private research centers.
L'archive ouverte pluridisciplinaire HAL, est destinée au dépôt et à la diffusion de documents scientifiques de niveau recherche, publiés ou non, émanant des établissements d'enseignement et de recherche français ou étrangers, des laboratoires publics ou privés. 


\title{
Food properties influence grasping strategies in strepsirrhines
}

\author{
LOUISE R. PECKRE ${ }^{1,2, *, \dagger}$, ANNE-CLAIRE FABRE ${ }^{1,3, *, \dagger}$, JULIEN HAMBUCKERS ${ }^{4,5}$, \\ CHRISTINE E. WALL ${ }^{6}$, LLUÍS SOCIAS-MARTÍNEZ ${ }^{2}$ and EMMANUELLE POUYDEBAT ${ }^{1}$
}

${ }^{1}$ UMR 7179 CNRS / MNHN, 57 rue Cuvier, Case postale 55, 75231, Paris Cedex 5, France

${ }^{2}$ Behavioural Ecology \& Sociobiology Unit, German Primate Centre, Leibniz Institute for Primate

Research, Kellnerweg 4, 37077, Göttingen, Germany

${ }^{3}$ Department of Life Sciences, The Natural History Museum, London SW7 5DB, UK

${ }^{4}$ Georg-August-Universität Göttingen, Faculty of Economic Sciences, Chair of Statistics, Humboldtallee

3, 37073 Göttingen, Germany

${ }^{5}$ HEC Liège, University of Liège, 14 rue Louvrex, 4000 Liège, Belgium

${ }^{6}$ Department of Evolutionary Anthropology, Duke University, Durham, NC 27708, USA

Received 12 October 2018; revised 18 December 2018; accepted for publication 18 December 2018

\begin{abstract}
Although hand grasping is ubiquitous in primate species, its origins remain uncertain. This is in part because uncertainty about hand skills and grasping strategies persists in strepsirrhines, a monophyletic group of primates located near the base of the primate tree. In this study, we report and discuss our observations of the different grasping strategies adopted by 85 captive individuals belonging to 22 species of strepsirrhines during the grasping of food items of different sizes and consistencies. Our results indicate that although strepsirrhines do not present variability in their hand-grip types (sole whole-hand power grip), they are able to adjust their grasping strategy depending on the properties of the food. Notably, they use the mouth when more precision is needed (i.e. to grasp small items). Moreover, grasping strategies adopted for big items differ depending on food consistency, revealing a new and potentially essential factor to consider in future research on grasping abilities. We believe that by looking across this important set of species in unconstrained standardized conditions, this study provides valuable insight for further comparative research on the potential selective pressures involved in the evolution of hand grasping.
\end{abstract}

ADDITIONAL KEYWORDS: consistency - grip type - power grip - prehension - primates - size - strepsirrhines.

\section{INTRODUCTION}

Prehensile behaviours, defined as 'the application of functionally effective forces by any appendage to an object for a task' (Sustaita et al., 2013: p. 381), are widespread among tetrapods. These prehensile behaviours are essential for a broad range of daily activities, with several body parts (e.g. tongue, mouth, tail, hand) being used to reach and grasp substrates, foods or partners (Karl \& Whishaw, 2013; Sustaita et al., 2013; Pouydebat et al., 2014; Brunon et al., 2014). Among these behaviours, hand grasping, particularly

*Corresponding authors. E-mail: louise.peckre@outlook.com, a.fabre@nhm.ac.uk

${ }^{\dagger}$ These authors contributed equally to this work. prominent in mammals and especially in primates, has been the focus of intense research.

Hand grasping is ubiquitous in primate species, but its origins remain uncertain. Historically, the main hypotheses on the origins of grasping abilities agree on the essential role of the selective pressures associated with the arboreal environment. Nevertheless, this arboreal environment itself appears not to be sufficient to explain the observed extant primate grasping abilities (Wood, 1916; Cartmill, 1972, 1974a, b, 1992; Rasmussen, 1990; Ravosa \& Dagosto, 2007; Ross \& Martin, 2007; Sussman et al., 2013). Current patterns of grasping abilities are likely to be the result of evolutionary processes induced by multiple selective pressures operating in different ecological and behavioural contexts. Although the literature usually discusses the origins and evolution of foot-grasping 
abilities in the context of locomotion, the foraging context is arguably essential when discussing handgrasping abilities (Pouydebat et al., 2008; Karl \& Whishaw, 2013; Sustaita et al., 2013).

Across all primate species, there exists a high variability of hand-grip types determined by the diversity of hand and digit postures (Macfarlane \& Graziano, 2009; Pouydebat et al., 2011; Reghem et al., 2012, 2013; Marzke et al., 2015). In 1956, Napier published a paper making a fundamental distinction between two main categories of hand-grip types. These two grip patterns are described by the terms 'precision' and 'power' grips and refer to both anatomical and functional aspects. Each grip presents a predominant power or precision function, which will determine hand posture. Hand-grip variability is also associated with particular morphological (morphometrical, muscular and articular) and neural traits that allow finger individualization and thumb opposability or pseudoopposability (Napier, 1960; Torigoe, 1985; Christel \& Fragaszy, 2000; Marzke \& Marzke, 2000; Castiello, 2005; Reghem et al., 2012). These features characteristic of catarrhines (Old World monkeys) and capuchins, all known for their manual dexterity, seem to be absent in strepsirrhines (lemuriforms and lorisiforms), which are thought to be more representative of the ancestral primates (Torigoe, 1985; Gebo, 2014). Hence, whereas catarrhines are known to show the highest variability of grips, including precision grips, when manipulating food, platyrrhines (New World monkeys) with the exception of capuchins, and strepsirrhines are thought to show a single stereotyped power-grip pattern consisting of a simultaneous movement of all digits to press the object against the palm (Napier, 1960; Bishop, 1962, 1964; Petter, 1962; Christel, 1993; Schöneich, 1993; Christel \& Fragaszy, 2000; Reghem et al., 2011, 2013). Uncertainty about hand skills in strepsirrhines persists, and some studies mention variation in manipulative patterns used by these species during more complex tasks (Jolly, 1964; Schöneich, 1993; Santos et al., 2005). This uncertainty probably arises, in part, from the fact that studies on the grasping abilities of strepsirrhines remain few and that several studies have described strepsirrhines as using the mouth preferentially when grasping immobile food items (Schöneich, 1993; Nekaris, 2005; Reghem et al., 2011, 2013). In contrast, other studies suggest that mouth grasping might not be as prominent (Ward et al., 1990; Dodson et al., 1992; Reghem et al., 2011). Several strepsirrhine species indeed use either their hand(s) or mouth when grasping food, depending on the properties of the food (Schöneich, 1993; Nekaris, 2005; Reghem et al., 2011, 2013; Sustaita et al., 2013).

Interestingly, several studies suggested that the grasping patterns used by primates are based on extrinsic properties (e.g. size, mobility) of the object grasped (Elliott \& Connolly, 1984; Cutkosky, 1989;
Cutkosky \& Howe, 1990; Santello et al., 2002; Pouydebat et al., 2009). In particular, the effect of the size of an object on grasping behaviour has been tested, revealing an impact on the grasping strategy adopted (Napier, 1956; Bishop, 1962; Christel, 1993; Jones-Engel \& Bard, 1996; Marzke \& Marzke, 2000; Pouydebat et al., 2009, 2010, 2011; Reghem et al., 2011; Marzke et al., 2015) and on the kinematics of prehension (Roy et al., 2002). In catarrhines, small food items have been shown to elicit more precision grips, whereas larger food items involve mainly the use of power grips (Bishop, 1964; Christel, 1993; Reghem et al., 2013; Marzke et al., 2015). In strepsirrhines, this effect has been tested only in the grey mouse lemur (Microcebus murinus). In M. murinus, smaller food items result in more mouth grasps, whereas larger food items lead to enhanced hand use (Reghem et al., 2011). In strepsirrhines, other studies have shown a preference for mouth grasping when grasping static food items and a preference for grasping strategies involving hand(s) when grasping mobile prey (Nekaris, 2005; Siemers et al., 2007; Scheumann et al., 2011; Toussaint et al., 2013, 2015; Peckre L., Lowie A., Wall C., Pouydebat E. \& Fabre A-C., unpublished observations). Moreover, although there is a more substantial literature on the effects of the object size, food consistency also appears potentially to be an important factor influencing grasping strategies. For example, food item consistency has been pointed out as playing an essential role in food choice and bite size (Hartstone-Rose et al., 2015; Taniguchi, 2015; Chalk et al., 2016; Chalk-Wilayto et al., 2016). Few studies have quantified the effect of food consistency on grasping behaviours. Indeed, some studies used food items of different consistencies but associated with different sizes (Table 1; Hopkins et al., 2002; Reghem et al., 2013).

Hence, although strepsirrhines are a monophyletic group of primates located near the base of the primate tree, their food-grasping strategies remain very poorly explored. In this study, we report and discuss our observations of the different grasping strategies adopted across 22 species of strepsirrhines, including six of the seven strepsirrhine families, when grasping food items with different properties (i.e. size and consistency). Based on previous studies, we predict: (1) that smaller food items will be associated with more mouth-grips and fewer hand(s)-grips than larger food items; and (2) that food consistency will influence grasping strategies (Table 1). We argue that by looking across this broad set of species in unconstrained standardized conditions, this study provides valuable insight into the understanding of the multiple factors influencing the choice of a grasping strategy in strepsirrhines. Thereby, this study constitutes an important new dataset to further comparative research discussing the potential selective pressures involved in the evolution of hand grasping in primates. 


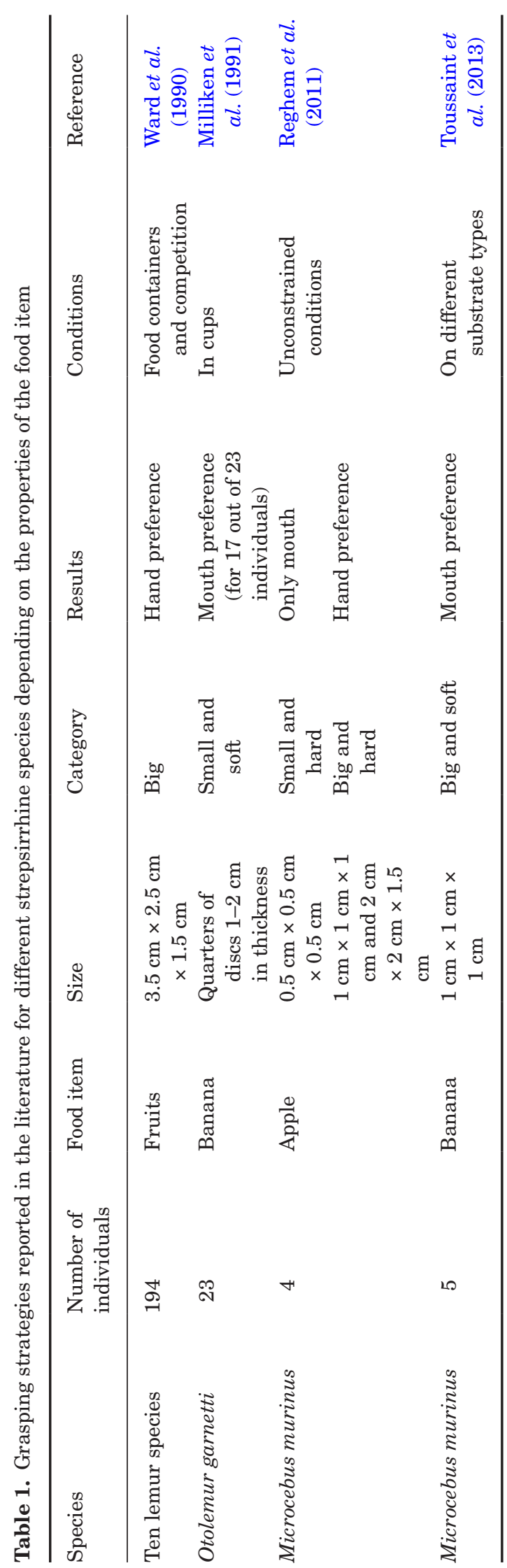

\section{MATERIAL AND METHODS}

\section{Sample}

We collected data for 85 individuals (42 females and 43 males) of 22 different species of strepsirrhines, including six of the seven strepsirrhine families (Cheirogaleidae, Daubentoniidae, Indriidae, Lemuridae, Galagidae and Lorisidae), excluding Lepilemuridae (see also Supporting Information, Appendix S1). Greater bamboo lemurs, Hapalemur simus, were recorded at Vincennes Zoo (Paris, France). The size of their enclosure was $6 \mathrm{~m} \times 12 \mathrm{~m} \times 5 \mathrm{~m}$. Grey slender lorises, Loris lydekkerianus, and Senegal bushbabies, Galago senegalensis, were recorded at the Antwerp Zoo (Antwerp, Belgium). The size of the grey slender lorises' enclosure was $5 \mathrm{~m} \times 5 \mathrm{~m} \times 3 \mathrm{~m}$, and the enclosure for the Senegal bushbabies was $4 \mathrm{~m} \times 12 \mathrm{~m} \times 3 \mathrm{~m}$. We recorded all the other species at the Duke Lemur Centre (Durham, NC, USA). Information about housing conditions and enrichment at the Duke Lemur Centre is provided online (https://lemur.duke.edu/discover/forresearchers/facilities/). Animal handling was performed in compliance with the International Primatological Society (IPS) Guidelines for the Use of Nonhuman Primates in Research according to protocol \#A08914-04, approved by the Duke University Institutional Animal Care and Use Committee. For each individual, relative age was calculated by dividing the age of the individual by the longevity of the species in question (based on Zehr et al., 2014).

\section{Behavioural data collection}

We videotaped each individual in its home enclosure for several days during its feeding period while eating its usual diet. The usual diet was constituted of different food items (see also Supporting Information, Appendix S2), including raw pre-cut pieces of fruits and vegetables in addition to monkey chow (Labdiet Monkey Diet Jumbo Constant Nutrition and ZuPreem Primate Dry Diet). Although insects are part of the diet for some species, we did not analyse prehension for these items. We used digital video cameras (SONY HDR-PJ790V, full HD 1080, 24.1MP; SONY HDR-SR11, 10.2MP; SONY Handycam, HDR-PJ230, 8.9MP; and SONY HDR-CX240E, full HD 1080, 9.2MP) for the diurnal species, and a low-light digital video camera (SONY HDR-SR11 10.2MP) for the nocturnal species.

We annotated every instance of identifiable food item grasping and analysed a total of 4823 grips for $102.06 \mathrm{~h}$ of video using Avidemux v.2.6.8 (Free Software Foundation, Inc.). The mean number of grips recorded per individual was $57 \pm 4$ grips. We characterized the different grasping strategies by the body part(s) closing on the object when the food item was taken from its support. Thereby, we defined these grasping strategies as 'oral', when the 
individuals used only the mouth, 'unimanual' when they used one hand only, 'bimanual' when they used both hands simultaneously, and combined 'oral-unimanual' or combined 'oral-bimanual' when they used both the mouth and the hand(s) simultaneously.

For each grip, we annotated the properties of the food item. We considered an item as 'big' when it was larger than one hand width of the focal species and as 'small' otherwise. Choosing a relative measure of the size of the item was necessary to control for the high variability of body size across the species tested. Regarding its consistency, an item was classified as 'hard' when it imposed a significant resistance to the teeth, defined as at least as stiff (Young's modulus) and tough (fracture toughness) as cucumber, and as 'soft' otherwise (Alvarez et al., 2000; Hartstone-Rose et al., 2015; see also Supporting Information, Appendix S2). We chose cucumber as a reference because it represents the median in our range of items. Considering the high variability of the consistency of the items provided, we believe that this choice is meaningful. All items were presented to the animals on a flat surface, either on the ground level or on a raised platform, and either directly in contact with a flat surface or on a flat container (e.g. paper plate). Indeed, to reduce physical constraints and to allow full visual access to any grasping events, we chose never to present the food items in a bowl.

\section{Statistical analyses}

We analysed the data using R v.3.3.2 (R Core Team, 2016). Descriptive statistics (mean $\pm \mathrm{SEM}$ ) were calculated for each individual and averaged for each species to produce an illustrative figure (Fig. 1) and test the presence of phylogenetic signals as described at the end of this section. To visualize the behaviour variations between species further, we applied a principal components analysis (PCA) using the $\mathrm{R}$ function 'PCA' from the 'factoextra' package (Kassambara \& Mundt, 2017). This analysis was performed on the proportions of oral,
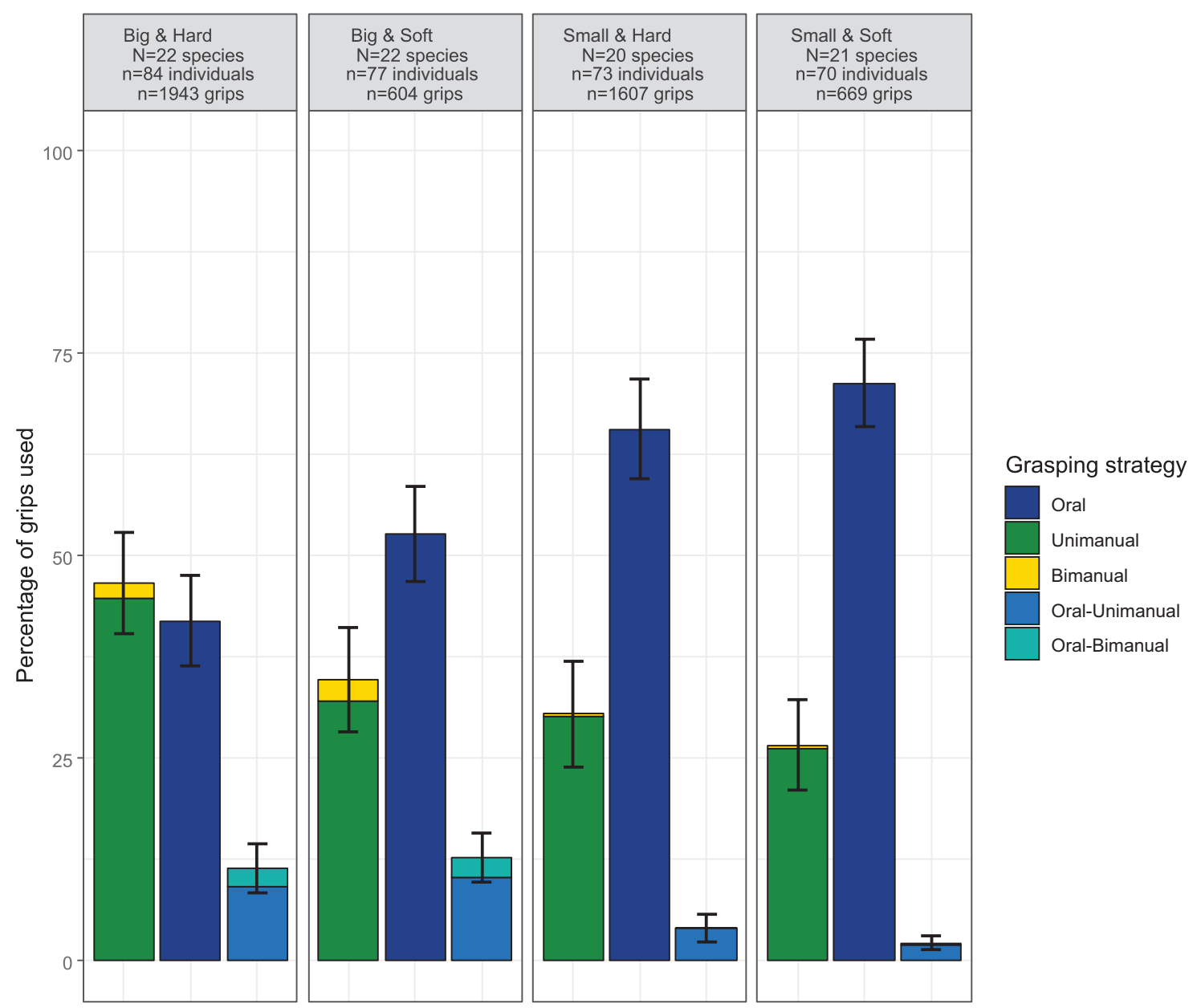

Figure 1. Percentage of grips observed with each grasping strategy depending on the properties (i.e. size and consistency) of the food item. 
unimanual and combined oral-unimanual grasping strategies used to grasp big and small items separately.

To investigate the effect of size, consistency, relative age, sex, the presence of a container and height on the grasping strategies adopted, we first ran a multinomial mixed model using the $R$ package MCMCglmm ('Markov chain Monte Carlo generalized linear mixed models'; Hadfield, 2010). In this model, we expressed the probability to adopt one of the grasping strategies as a function of our variables of interest (Table 2). To account for repeated measures and cluster-specific correlations, we included species and individual identity random intercepts. Given that the individuals used both bimanual and combined oralbimanual strategies in $<5 \%$ of the observed grips, we used only three broader grasping categories, namely oral, manual (unimanual or bimanual) and combined oral-manual (combined oral-unimanual or combined oral-bimanual). The sample for this model consisted of 4823 grips performed by 85 individuals belonging to 22 species. Given that three individuals were the only representatives of their species, we grouped them with the individuals of their phylogenetically closest sister species to allow treatment of the species-specific effect as a random factor. Hence, we grouped the Otolemur crassicaudatus with the Galago senegalensis, the Eulemur albifrons with the Eulemur rufus, and the Nycticebus coucang with the Nycticebus pygmaeus (see also Supporting Information, Appendix S1). Given that the effect of the phylogenetic history on these behavioural traits is not straightforward, we also ran the models while grouping the three individuals that were the only representatives of their species under the same fictive species. The results obtained with both grouping methods were similar; therefore, we chose to present the results of only the first method.

To explore independently how the different variables of interest influenced the two most commonly observed grasping strategies (mouth and unimanual grips), we fitted a generalized linear mixed model (GLMM; Baayen et al., 2008) with a binomial response distribution and a logit link function using the 'lme4' $R$ package (Bates et al., 2015). As in the multinomial model described previously, we included individual and species-specific random intercepts. For both strategies independently, we performed sequential likelihood-ratio tests by adding one fixed effect after another and by comparing the full model with the null model using the $R$ function 'ANOVA' (see also Supporting Information, Appendix S3). The final models (M5.0 and UM4.0, Tables 3 and 4) included as fixed effects the size, the consistency and the height, in addition to an interaction term between size and consistency. Additionally, the final model for the mouth-grasping strategy (M5.0) also included as a fixed effect the presence of a container. Age and sex were excluded from these models by the model selection procedure. As random effects, we included species, individual identity and dates, in addition to species-specific random slopes for the effect of the interaction between size and consistency. Visual inspection of residual plots did not reveal any obvious deviations from homoscedasticity or normality (see also Supporting Information, Appendices S4 and S5). To assess the goodness of fit of the final model, we used the R package "DHARMa" (Diagnostics for HierArchical Regression Models; (Hartig, 2018; see also Supporting Information, Appendices S4 and S5).

We considered variants of these full models on subsets of our data to assess the robustness of our analysis (Tables 3 and 4). First, these models were run independently for big (M5.1 and UM4.1) and small items (M5.2 and UM4.2). Second, we ran these models on datasets including either only the grips observed in above-ground height condition (M5.3 and UM4.3) or only the grips observed in the absence of a container (M5.5), these two conditions being the most represented ones. Finally, we ran these full models on datasets including only the individuals tested either in both height conditions (M5.4 and UM4.4) or in both container conditions (M5.6). The different sample sizes corresponding to each dataset can be found in Tables 3 and 4.

We express the results in terms of odds, which are the number of times success occurred compared with the number of times failure occurred (Fulton et al., 2012). In contrast to probabilities ranging from zero to one, odds can range from zero to positive infinity; odds greater than one indicate that success is more likely than failure, whereas odds less than one indicate that failure is more likely than success.

We tested the presence of a phylogenetic signal independently in the grasping behaviours associated with the three categories for which behaviours were observed to differ: big and hard, big and soft, and small items. We used the multivariate $K$-statistic $\left(K_{\text {mult }}\right)$ assessed with the $\mathrm{R}$ 'physignal' function included in the 'geomorph' package (Adams, 2014; Adams et al., 2018). The $K$-value is a scaling parameter for the correlations between species traits, relative to the correlation expected under Brownian motion. Values of $K<1.0$ correspond to traits being less similar among species than expected based on their phylogenetic relationships. This method requires the use of a phylogenetic tree. We used a consensus tree in v. 3 of the 10kTrees Project (Arnold et al., 2010). Using the same method, we also tested the presence of a phylogenetic signal in the coefficient of the effect of the interaction between size and consistency on the oral- and unimanual-grasping behaviour. We extracted these coefficients from the GLMMs run without pooling the three species represented by only one individual with their sister species. 


\section{RESULTS}

Grasping patterns

The two most frequently observed grasping strategies used to grasp immobile food items across species were unimanual and mouth-grips (Fig. 1). Other grip types, including combined mouth-unimanual grips or mouth-bimanual grips and bimanual grips, were also observed in moderate proportions (Fig. 1). Concerning hand grasping, we observed a single power-grip pattern in all grip events recorded. The scatter plot of the first

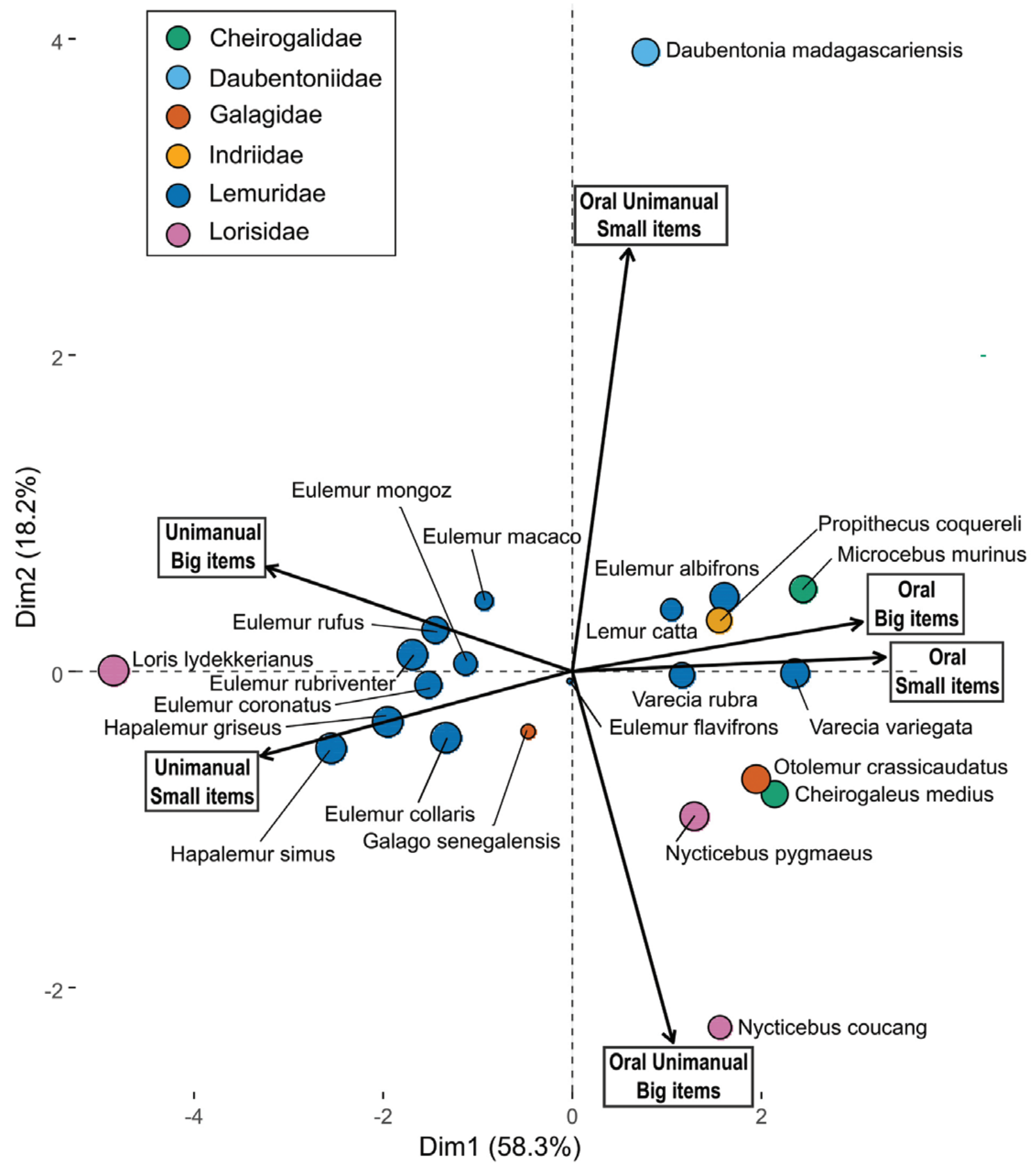

Figure 2. Cloud of individuals ( $N=22$ species) on the first two dimensions of the principal components analysis run on the three main grasping strategies. Colours represent the six extant families of strepsirrhines included in the study. The size of each circle represents the importance of the first component for a given species $\left(\cos ^{2}\right)$. 
two principal components is presented in Figure 2. Eigenvalues of these two principal components were 3.5 and 1.1, respectively, accounting for $76.5 \%$ of the total variance. The first principal component (Dim1, accounting for $58.3 \%$ of the variance) was positively correlated with the proportions of oral grasping for both small and big items and negatively correlated with the proportion of unimanual grasping for both sizes. The second principal component (Dim2, accounting for $18.2 \%$ of the variance) was positively correlated with the proportion of oral-unimanual grasping of small items and negatively correlated with the proportion of oral-unimanual grasping for big items. This PCA shows that the species that prefer the oral-grasping strategy over the unimanual-grasping strategy exhibit this preference for both big and small items.

\section{Variables influencing the grasping strategy}

The multinomial model revealed significant effects of food item size and consistency on the grasping strategy adopted (Table 2). When the item was big and hard, the probability of choosing the mouth to grasp the item was significantly higher than the probability of choosing the hand(s) $[\beta=2.31,95 \%$ confidence interval (CI) 1.45-3.07; $P<0.001$; Table 2]. In the same conditions, the probability of choosing a mouthhand(s) combined strategy to grasp the item was significantly lower than the probability of choosing the hand(s) $(\beta=-2.90,95 \%$ CI -4.42 to $-1.37 ; P<0.001$; Table 2). In terms of the odds comparisons, there were $10 \%$ more chances to select the mouth rather than the hand(s) and $94 \%$ more chances to select the hand(s) rather than a combination of hand(s) and mouth to grasp a big and hard item. When the item was small, the relative probability of choosing the mouth strategy to grasp the item rather than the hand(s) improved by a factor of seven ( $\beta=1.92,95 \%$ CI 1.69-2.17; $P<0.001$; Table 2; Fig. 1). In contrast, when the item was small, the probability of choosing a mouth-hand(s) combined strategy decreased by a factor of $0.4(\beta=-0.79,95 \%$ CI -1.21 to $-0.34 ; P<0.001$; Table $2 ;$ Fig. 1 ). When the item was soft, the relative probability of choosing the mouth strategy to grasp the item rather than the hand(s) improved the odds by a factor of $1.6(\beta=0.47,95 \%$ CI 0.21-0.72; $P<0.001$; Table 2 ; Fig. 1 ). We observed a similar effect for the odds associated with the mouthhand(s) combined strategy; a soft consistency improved the odds by a factor of 1.8 ( $\beta=0.59,95 \%$ CI $0.16-1.00$; $P=0.01$; Table 2; Fig. 1). The probability of choosing the hand(s) was, nevertheless, still considerably higher than the probability of choosing a mouth-hand(s) combined strategy (in these conditions, by $90 \%$ ).

Moreover, the model also revealed a significant effect of the height of the feeding platform and a tendency for an effect of the presence of a container. When the individual was on the ground, the relative probability of choosing the hand(s) to grasp an item was increased by a factor four $(\beta=1.37,95 \%$ CI $0.92-1.87 ; P<0.001$; Table 2 ). When the individual was tested with a container, the relative probability of choosing the hand(s) to grasp an item was decreased by a factor $0.7(\beta=-0.31,95 \%$ CI -0.63 to $0.02 ; P=0.071$; Table 2 ). This model could not detect any effect of relative age $(P=0.47)$ or sex $(P=0.70)$ on grasping strategies (Table 2$)$.

\section{Effects of size and consistency}

The interaction between size and consistency significantly influenced the probability of both mouthgrips $(P=0.005$; Table 3, M5.0) and unimanual grips $(P=0.002$; Table 4, UM4.0).

Table 2. Fixed effects of the Markov chain Monte Carlo generalized linear mixed models

\begin{tabular}{|c|c|c|c|c|c|c|}
\hline \multirow[t]{2}{*}{ Effects } & \multirow[t]{2}{*}{$\begin{array}{l}\text { Posterior } \\
\text { mean }\end{array}$} & \multicolumn{2}{|c|}{$\begin{array}{l}95 \% \text { Confidence } \\
\text { interval }\end{array}$} & \multirow{2}{*}{$\begin{array}{l}\text { Effective } \\
\text { sample } \\
\text { size }\end{array}$} & \multirow[t]{2}{*}{$P$-value } & \\
\hline & & Lower & Upper & & & \\
\hline Intercept: mouth and hand(s) & -2.90 & -4.42 & -1.37 & 483.50 & $<0.001$ & $* * *$ \\
\hline Intercept: mouth & 2.31 & 1.45 & 3.07 & 303.70 & $<0.001$ & $* * *$ \\
\hline Sex: male & -0.16 & -0.99 & 0.82 & 282.20 & 0.6976 & \\
\hline Age relative & -0.39 & -1.45 & 0.62 & 284.80 & 0.468 & \\
\hline Height above ground & 1.37 & 0.92 & 1.87 & 559.00 & $<0.001$ & $* * *$ \\
\hline Container: none & -0.31 & -0.63 & 0.02 & 552.00 & 0.0712 & \\
\hline Mouth and hand(s): size small & -0.79 & -1.21 & -0.34 & 111.40 & $<0.001$ & $* * *$ \\
\hline Mouth: size small & 1.92 & 1.69 & 2.17 & 329.40 & $<0.001$ & $* * *$ \\
\hline Mouth and hand(s): consistency soft & 0.59 & 0.16 & 1.00 & 149.40 & 0.01 & * \\
\hline Mouth: consistency soft & 0.47 & 0.21 & 0.72 & 548.20 & $<0.001$ & $* * *$ \\
\hline
\end{tabular}

$*, * *$ and $* * *$ indicate coefficients found significant at the $5 \%, 1 \%$ and below $1 \%$ test level, respectively. A dot (.) indicates coefficients found significant at the $10 \%$ test level. 
Table 3. Fixed effects associated with the mouth-grasping models

\begin{tabular}{|c|c|c|c|c|c|c|c|c|}
\hline Fixed effects & Estimate & $\mathrm{SE}$ & $z$-value & $P$-value & & $\begin{array}{l}\text { Number } \\
\text { of grips }\end{array}$ & $\begin{array}{l}\text { Number } \\
\text { of species }\end{array}$ & $\begin{array}{l}\text { Number of } \\
\text { individuals }\end{array}$ \\
\hline \multicolumn{6}{|l|}{ Full model (M5.0) } & 4823 & $22(19)$ & 85 \\
\hline (Intercept) & -0.73 & 0.46 & -1.59 & 0.112 & & & & \\
\hline Size (small) & 1.72 & 0.22 & 7.86 & $<0.001$ & $* * *$ & & & \\
\hline Consistency (soft) & 0.61 & 0.28 & 2.15 & 0.031 & $*$ & & & \\
\hline Height (up) & 0.70 & 0.25 & 2.79 & 0.005 & $* *$ & & & \\
\hline Container (none) & -0.43 & 0.17 & -2.44 & 0.015 & $*$ & & & \\
\hline $\begin{array}{l}\text { Size } \times \text { consistency } \\
(\text { small, soft })\end{array}$ & -0.68 & 0.24 & -2.84 & 0.005 & $* *$ & & & \\
\hline \multicolumn{6}{|c|}{ Model on big items (M5.1) } & 2547 & 22 (19) & 84 \\
\hline Consistency (soft) & 0.62 & 0.28 & 2.23 & 0.026 & $*$ & & & \\
\hline Height (up) & 0.98 & 0.34 & 2.90 & 0.004 & $* *$ & & & \\
\hline Container (none) & -0.47 & 0.22 & -2.20 & 0.028 & $*$ & & & \\
\hline \multicolumn{6}{|c|}{ Model on small items (M5.2) } & 2276 & $22(19)$ & 84 \\
\hline Consistency (soft) & -0.10 & 0.31 & -0.32 & 0.753 & & & & \\
\hline Height (up) & 0.35 & 0.38 & 0.94 & 0.348 & & & & \\
\hline Container (none) & -0.07 & 0.28 & -0.24 & 0.808 & & & & \\
\hline \multicolumn{6}{|c|}{ Model on above-ground condition (M5.3) } & 4076 & $20(18)$ & 76 \\
\hline (Intercept) & -0.03 & 0.41 & -0.08 & 0.933 & & & & \\
\hline Size (small) & 1.72 & 0.22 & 7.73 & $<0.001$ & $* * *$ & & & \\
\hline Consistency (soft) & 0.67 & 0.32 & 2.08 & 0.038 & * & & & \\
\hline Container (none) & -0.51 & 0.20 & -2.56 & 0.011 & $* *$ & & & \\
\hline $\begin{array}{l}\text { Size } \times \text { consistency } \\
(\text { small, soft })\end{array}$ & -0.82 & 0.27 & -3.04 & 0.002 & $* *$ & & & \\
\hline \multicolumn{6}{|c|}{ Full model on individuals tested in both height conditions (M5.4) } & 1274 & 12 & 18 \\
\hline (Intercept) & -1.73 & 0.53 & -3.25 & 0.001 & $* *$ & & & \\
\hline Size (small) & 1.68 & 0.38 & 4.42 & $<0.001$ & $* * *$ & & & \\
\hline Consistency (soft) & 0.44 & 0.38 & 1.16 & 0.245 & & & & \\
\hline Height (up) & 1.08 & 0.29 & 3.77 & $<0.001$ & $* * *$ & & & \\
\hline Container (none) & -0.32 & 0.30 & -1.08 & 0.280 & & & & \\
\hline $\begin{array}{l}\text { Size } \times \text { consistency } \\
(\text { small, soft })\end{array}$ & -0.01 & 0.52 & -0.02 & 0.983 & & & & \\
\hline \multicolumn{6}{|c|}{ Model on non-container condition (M5.5) } & 3391 & $19(17)$ & 71 \\
\hline (Intercept) & -1.26 & 0.45 & -2.83 & 0.005 & $* *$ & & & \\
\hline Size (small) & 2.09 & 0.24 & 8.67 & $<0.001$ & $* * *$ & & & \\
\hline Consistency (soft) & 0.70 & 0.32 & 2.16 & 0.031 & $*$ & & & \\
\hline Height (up) & 0.73 & 0.29 & 2.51 & 0.012 & $*$ & & & \\
\hline $\begin{array}{l}\text { Size } \times \text { consistency } \\
(\text { small, soft })\end{array}$ & -0.67 & 0.31 & -2.16 & 0.031 & * & & & \\
\hline \multicolumn{6}{|c|}{ Full model on individuals tested in both container conditions (M5.6) } & 2084 & 12 & 33 \\
\hline (Intercept) & -0.77 & 0.50 & -1.52 & 0.129 & & & & \\
\hline Size (small) & 1.52 & 0.42 & 3.65 & $<0.001$ & $* * *$ & & & \\
\hline Consistency (soft) & -0.02 & 0.43 & -0.05 & 0.963 & & & & \\
\hline Height (up) & 0.83 & 0.30 & 2.77 & 0.006 & $* *$ & & & \\
\hline Container (none) & -0.41 & 0.17 & -2.37 & 0.018 & $*$ & & & \\
\hline $\begin{array}{l}\text { Size } \times \text { consistency } \\
(\text { small, soft })\end{array}$ & -0.18 & 0.59 & -0.31 & 0.759 & & & & \\
\hline
\end{tabular}

$*$, ** and $* * *$ indicate coefficients found significant at the $5 \%, 1 \%$ and below $1 \%$ test level, respectively. A dot (.) indicates coefficients found significant at the $10 \%$ test level.

To grasp small items, the probability of using mouthgrips, relative to the probability of using another strategy, was significantly higher $(\beta=1.73 \pm 0.22$;
$P<0.001$; Table 3, M5.0), and the relative probability of choosing unimanual grips was significantly lower $(\beta=-1.47 \pm 0.31 ; P<0.001 ;$ Table 4, UM4.0) than 
Table 4. Fixed effects associated with the unimanual grasping models

\begin{tabular}{|c|c|c|c|c|c|c|c|c|}
\hline Fixed effects & Estimate & $\mathrm{SE}$ & $z$-value & $P$-value & & $\begin{array}{l}\text { Number } \\
\text { of grips }\end{array}$ & $\begin{array}{l}\text { Number } \\
\text { of species }\end{array}$ & $\begin{array}{l}\text { Number of } \\
\text { individuals }\end{array}$ \\
\hline \multicolumn{6}{|l|}{ Full model (UM4.0) } & \multirow[t]{6}{*}{4823} & \multirow[t]{6}{*}{$22(19)$} & \multirow[t]{6}{*}{85} \\
\hline (Intercept) & -0.13 & 0.59 & -0.22 & 0.829 & & & & \\
\hline Size (small) & -1.37 & 0.28 & -4.92 & $<0.001$ & $* * *$ & & & \\
\hline Consistency (soft) & -0.82 & 0.31 & -2.65 & 0.008 & $* *$ & & & \\
\hline Height (up) & -0.52 & 0.23 & -2.20 & 0.028 & $*$ & & & \\
\hline $\begin{array}{l}\text { Size } \times \text { consistency } \\
(\text { small, soft })\end{array}$ & 0.98 & 0.28 & 3.51 & $<0.001$ & $* *$ & & & \\
\hline \multicolumn{6}{|c|}{ Model on big items (UM4.1) } & \multirow[t]{4}{*}{2547} & \multirow[t]{4}{*}{$22(19)$} & \multirow[t]{4}{*}{84} \\
\hline (Intercept) & 0.23 & 0.57 & 0.40 & 0.689 & & & & \\
\hline Consistency (soft) & -0.90 & 0.31 & -2.94 & 0.003 & $* *$ & & & \\
\hline Height (up) & -0.91 & 0.30 & -3.04 & 0.002 & $* *$ & & & \\
\hline \multicolumn{6}{|c|}{ Model on small items (UM4.2) } & \multirow[t]{4}{*}{2276} & \multirow[t]{4}{*}{$22(19)$} & \multirow[t]{4}{*}{84} \\
\hline (Intercept) & -1.84 & 0.69 & -2.68 & 0.007 & $* *$ & & & \\
\hline Consistency (soft) & 0.18 & 0.33 & 0.56 & 0.578 & & & & \\
\hline Height (up) & -0.41 & 0.36 & -1.13 & 0.259 & & & & \\
\hline \multicolumn{6}{|c|}{ Model on above-ground condition (UM4.3) } & \multirow[t]{5}{*}{4076} & \multirow[t]{5}{*}{$20(18)$} & \multirow[t]{5}{*}{76} \\
\hline (Intercept) & -0.69 & 0.58 & -1.196 & 0.232 & & & & \\
\hline Size (small) & -1.35 & 0.29 & -4.687 & $<0.001$ & $* * *$ & & & \\
\hline Consistency (soft) & -0.88 & 0.34 & -2.633 & 0.008 & $* *$ & & & \\
\hline $\begin{array}{l}\text { Size } \times \text { consistency } \\
(\text { small, soft })\end{array}$ & 1.19 & 0.31 & 3.790 & $<0.001$ & $* * *$ & & & \\
\hline \multicolumn{6}{|c|}{ Full model on individuals tested in both height conditions (UM4.4) } & \multirow[t]{6}{*}{1274} & \multirow[t]{6}{*}{12} & \multirow[t]{6}{*}{18} \\
\hline (Intercept) & 1.04 & 0.46 & 2.27 & 0.023 & $*$ & & & \\
\hline Size (small) & -0.98 & 0.30 & -3.21 & 0.001 & $* *$ & & & \\
\hline Consistency (soft) & -0.68 & 0.38 & -1.77 & 0.077 & . & & & \\
\hline Height (up) & -0.93 & 0.25 & -3.67 & $<0.001$ & $* * *$ & & & \\
\hline $\begin{array}{l}\text { Size } \times \text { consistency } \\
(\text { small, } \text { soft })\end{array}$ & -0.37 & 0.52 & -0.71 & 0.478 & & & & \\
\hline
\end{tabular}

$*, * *$ and $* * *$ indicate coefficients found significant at the $5 \%, 1 \%$ and below $1 \%$ test level, respectively. A dot (.) indicates coefficients found significant at the $10 \%$ test level.

when grasping big items. These effects were confirmed when using more restrictive datasets (Table 3, M5.3, M5.4, M5.5 and M5.6; and Table 4, UM4.3 and UM4.4).

The relative probability of using mouth-grips $(\beta=0.65 \pm 0.28 ; P=0.020 ;$ M5.0) was significantly higher and the relative probability of using unimanual grips lower $(\beta=-0.82 \pm 0.31 ; P=0.007$; UM4.0) when grasping soft items than when grasping hard ones. Independent models run on big and small items separately revealed that these effects were persistent only for big items ( $\beta=0.66 \pm 0.27 ; P=0.015 ; \mathrm{M} 5.1$; and $\beta=-0.91 \pm 0.30 ; P=0.003 ; \mathrm{UM} 4.1$, respectively).

These effects of food consistency were verified when considering only the grips in the above-ground conditions and when considering only the grips in the non-container conditions (Table 3, M5.3 and M5.5; and Table 4, UM4.3), but were not present in more restrictive datasets considering only individuals tested in both the container or the above-ground conditions (Table 3, M5.4 and M5.6; and Table 4, UM4.4).

\section{Phylogenetic signals}

There was a significant but weak phylogenetic signal in the grasping behaviours associated with big and hard $\left(K_{\text {mult }}=0.37 ; P=0.008\right)$ and with big and soft items $\left(K_{\text {mult }}=0.37 ; P=0.007\right)$ but not with small items $\left(K_{\text {mult }}=0.27 ; P=0.128\right)$. Interestingly, weak but significant phylogenetic signals were also found in the effect of the interaction size $\times$ consistency $\left(K_{\text {mult }}=0.32\right.$; $P=0.011$; Fig. 3 ).

\section{Effect of height}

The relative probability of grasping food items with the mouth $(\beta=0.69 \pm 0.25 ; P=0.006$; Table 3, M5.0) was significantly higher and the relative probability of grasping the item with one hand significantly lower $(\beta=-0.52 \pm 0.23 ; P=0.024$; Table 4, UM4.0) when the individuals were tested above the ground than when tested at ground level. These effects were present when 


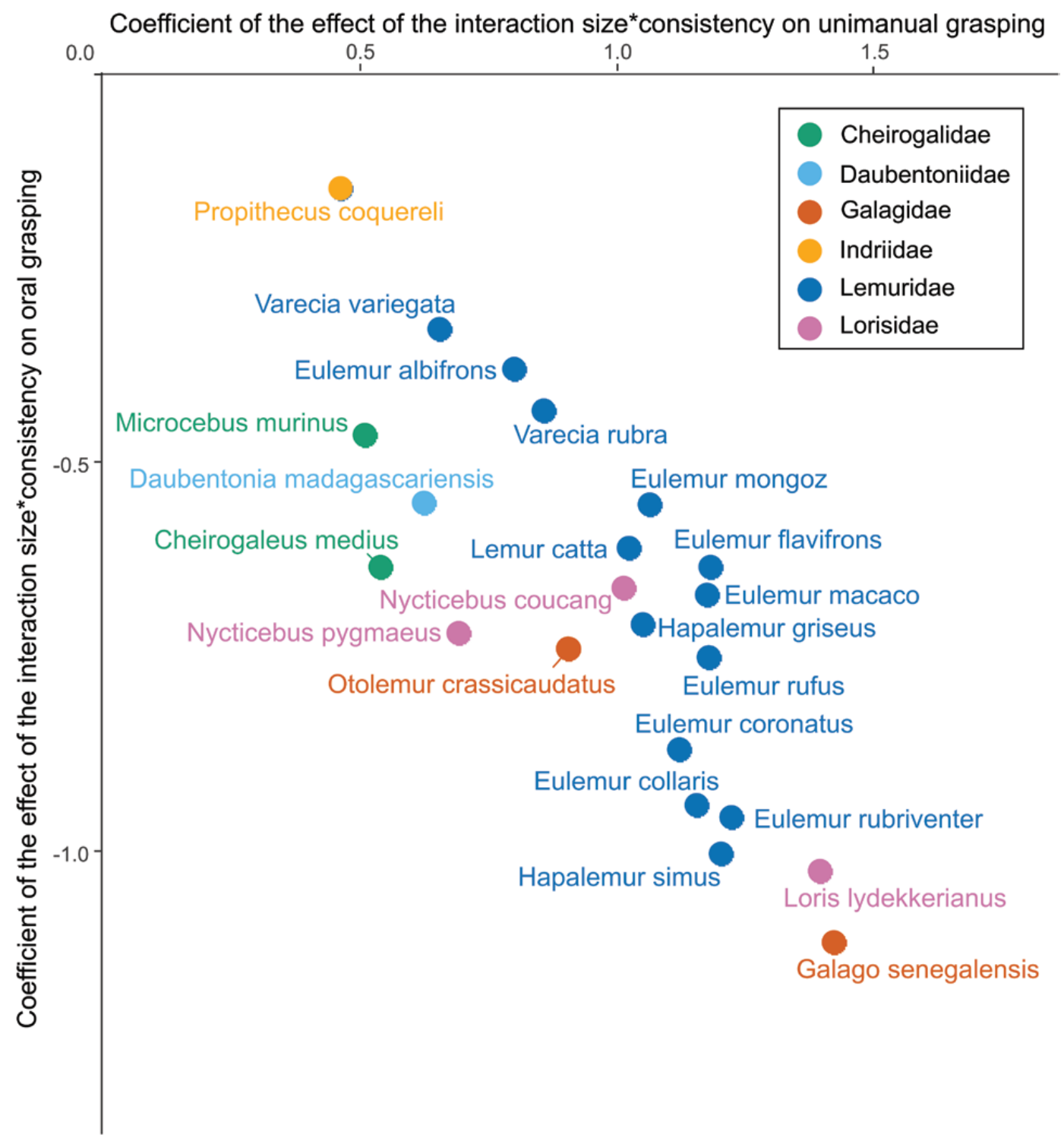

Figure 3. Coefficients of the generalized linear mixed models of the effect of the interaction between food item size and consistency on oral and unimanual grasping behaviours for each species $(N=22$ species). Colours represent the six extant families of strepsirrhines included in the study.

tested for big items only $(\beta=0.96 \pm 0.33 ; P=0.004$; Table 3, M5.1; and $\beta=-0.91 \pm 0.30 ; P=0.002$; Table 4, UM4.1, respectively), but not for small items only (Table 3, M5.2; and Table 4, UM4.2).These effects were also present when tested only on the individuals that had been observed in both height conditions $(\beta=1.08 \pm 0.29$; $P<0.001$; Table 3 , M5.4; and $\beta=-0.93 \pm 0.25 ; P<0.001$; Table 4, UM4.4, respectively).

Effect of the presence of a container

The relative probability of grasping an item with the mouth was significantly lower when the items were presented without a container $(\beta=-0.43 \pm 0.18$;
$P=0.013 ;$ Table 3, M5.0). This effect was present when tested for big items only $(\beta=-0.48 \pm 0.22 ; P=0.026$; Table 3, M5.1) but not for small items only (Table 3, M5.2). This effect was present when tested only on the individuals that had been observed in both container conditions $(\beta=-0.41 \pm 0.17 ; P=0.018$; M5.6: Table 3$)$.

\section{DISCUSSION}

In this study, we investigated the effect of food properties, namely size and consistency, on the associated grasping strategies adopted by 85 captive individuals across 22 species of strepsirrhines. Independently of these food 
properties, two grasping strategies prevailed, the oral and unimanual grips (Fig. 1). Species differered in the balance between these two main grasping strategies, but when grasping with the hand(s) the dynamic movement observed was constant and consisted, in accordance with the existing literature, of a sole (i.e. one) whole-hand power grip (Bishop, 1962, 1964; Schöneich, 1993; Christel \& Fragaszy, 2000; Reghem et al., 2011, 2013). Our results also showed that across all species, both the size and the consistency of the item significantly influence the grasping strategy adopted.

When grasping big items, the probability of choosing a mouth-grip over the other strategies is significantly lower than when grasping small items. In parallel, the probabilities of choosing manual or combined mouth-hand(s) strategies over the other strategies are significantly higher when grasping big items than when grasping small items. Hence, our results corroborate the hypothesis that, in strepsirrhines, big items elicit more hand grasping than small items (Reghem et al., 2011).

At the proximate level, this might be explained by the fact that the large gape associated with mouth grasping of big items would prevent effective food reduction by the teeth through its negative effect on bite force (Dumont \& Herrel, 2003). In contrast, the use of the hand(s) to grasp the item might allow the teeth more effectively to separate and chew smaller pieces from the larger item while the hand(s) stabilize it. Interestingly, ruffed lemurs (Varecia variegata and Varecia rubra) were observed to use comparatively few hand-grips compared with the other species. Nelson et al. (2009) have described an alternative strategy when Varecia ingests large food items by using head-tilting, whereby the head is rotated vertically during chewing. This positions the food on the premolar and molar teeth, thereby increasing effective bite force. Compared with other extant strepsirrhines, ruffed lemurs (Varecia spp.) also have long jaws, allowing them to open their mouth wider and accommodate large food items on the postcanine dentition (Perry et al., 2011).

In contrast, strepsirrhines use only a whole-hand power grip. This suggests that the precision needed to grasp small items is better provided by the mouth than by this power grip. In catarrhine species, the power grip also appears to be more prominent when grasping big objects than when grasping small objects, with small objects eliciting more precision grips (Pouydebat et al., 2009). Hence, in catarrhine species, precision grasping is provided by precision grips (Pouydebat et al., 2009), whereas in strepsirrhines it seems to be provided by structures in the mouth. In this sense, our study supports the idea that both grip categories might have evolved to fulfil different functions, and that precision grips are not merely a more elaborated version of power grips (Pouydebat et al., 2008). In strepsirrhines, species that all have the ability to grasp with the hand(s), mouth grasping seems to be an effective strategy to grasp small food items. Interestingly, although catarrhines use their hand(s), and particularly precision grips, to groom their partners, strepsirrhines use the tooth-comb.

Our results also showed a significant interaction term between size and consistency; although consistency does not seem to impact the grasping strategy associated with small items significantly, it does when considering big items. When grasping big items, if the item is soft the probabilities of choosing the mouth and combined mouth-hand(s) strategies over the other strategies increase significantly compared with the respective probabilities associated with hard items. Soft items are susceptible to falling apart when handled, resulting in food losses and juice spillage (Hartstone-Rose et al., 2015). Feeding may then be better optimized by mouth-grips, allowing for direct mouth processing and ingestion, especially as for these soft items the required bite force is far lower. The head-tilting behaviour of the ruffed lemur (Varecia spp.) has also been proposed to be more specifically associated with feeding on juicy items, to maximize the ingestion of calorie-rich juice (Hartstone-Rose A. and Perry J.M.G., personal communication). Additionally, an alternative strategy to deal with both food losses and bite force seems to include mouth-hand(s) combined grips, because the big and soft items are the ones that elicit the greater proportion of combined grips. Moreover, big and hard items are certainly the ones requiring the most processing before ingestion (Peckre L., Fabre A-C., Wall C. and Pouydebat E., unpublished data). In this sense, the increased proportion of hand grasping associated with these food items might be the result of direct biomechanical constraints but might also be the result of anticipation and/or the need to assist the oral structures used during processing.

Despite the extensive literature pointing out the importance of food consistency in the context of feeding behaviour, ontogeny and food processing (Perry et al., 2011; Taniguchi, 2015; Hartstone-Rose et al., 2015; Chalk et al., 2016), its influence on the grasping strategy adopted has not been explored. Previous studies on grasping behaviour in strepsirrhines focused on a restricted number of species (between one and ten) or/and food-item categories (one or two) (Table 1; Ward et al., 1990; Milliken et al., 1991; Scheumann et al., 2011; Toussaint et al., 2013). Categorizing the food items used in these studies in accordance with our definitions of size and consistency, we conclude that our findings on the effects of food properties on grasping strategies are consistent with the literature and generalizable to a broad range of strepsirrhine species. 
Additionally, we show that the height at which the individuals are tested (on the ground or on a raised platform) significantly influences the strategy used to grasp big food items. When the individuals are tested on the ground, they are more likely to choose the unimanual strategy rather than choosing the mouth to grasp these big items. On the ground, the individuals are more exposed to conspecifics that might take their food and to predators. In the wild, several primate species show an increased vigilance when on the ground (Gould \& Sauther, 2007). Grasping with the hand(s) would allow an individual to remain vigilant while grasping the food. Even though a predation threat does not exist in captivity, the individuals also appeared to be more alert while on the ground, as evidenced by frequent head and neck movements to scan the environment. Antipredator vigilance behaviours may be evolutionarily fixed behaviours independent of the life of the individual itself (Blumstein, 2006). Moreover, when on the ground the risk of losing the food item with a failed grasping attempt is reduced when compared with when the individual is above the ground. Hence, using a less accurate grasping strategy would represent a cost easily balanced by an increased vigilance on the surrounding environment.

Our results also showed an effect of the presence of a container on the relative probability of grasping the item with the mouth. When the food item was presented with a container, the probability of using the mouth-grip rather than another strategy was higher. Here, the explanation may be less straightforward, but several hypotheses may be formulated. First, this effect might be attributable to an associated factor not considered here. For instance, the item presented in a container might be less dispersed than the ones presented directly on the flat surface. In this context, the increased proportion of hand(s)-grips when the food items are presented without a container could be caused by an increased distance between the individual and some of the food items. Another possible reason for this effect could be a hygienic behavioural avoidance strategy, considering that the container is probably less contaminated than the flat surface. These hygienic behaviours appear to be relatively common in multiple taxa (Curtis, 2014). Nevertheless, this effect appears to be relatively moderate; the effect of size and consistency on mouth-grip proportion is also present when considering only the non-container conditions. Overall, our results reveal the importance of recognizing and controlling for multiple factors when studying grasping strategies, especially in a comparative context.

The PCA indicated that for a given species the propensity to use the oral grasping strategy is consistent for both size categories (Fig. 2). Moreover, the presence of weak phylogenetic signals associated with the grasping strategies used to grasp big items and with the effect of the interaction between size and consistency on grasping behaviour (Figs 2,3) also indicates that closely related species have a more similar behavioural pattern. In the aye-aye, Daubentonia madagascariensis, an extractive forager presenting specific morphological adaptations associated with an unusual foraging behaviour, oral grasping was also significantly increased when grasping small items. Wild ayeayes tap wood with their enlarged fourth digit to locate hollow regions before gnawing the wood and extracting larvae with their elongated third digit (Lhota et al., 2009). This particular morphological adaptation might explain why combined oralunimanual grasping was also significantly increased when grasping small items in this species (Fig. 2). In the present study, our relatively low sample size per species does not allow discussion of the specieslevel patterns in detail but provides valuable insights into comparative approaches concerning the evolution of hand grasping of food in primates. The observed differences between species in grasping strategies are most probably the result of complex co-evolutionary processes associated with different behavioural contexts, such as locomotion or social interactions. For example, variation in the propensity to use the hand(s) across strepsirrhine species has been suggested to be associated with their pattern of infant carriage (in the mouth or clinging onto their fur; Peckre et al., 2016).

Strepsirrhines are mainly arboreal, and this environment provides multiple additional constraints, including the need to maintain body balance. In the wild, strepsirrhines are regularly observed pulling a branch and bringing the item of interest (fruit, leaf or flower) closer to their mouth before grasping it with the mouth. The second hand appears to participate in maintaining balance. Food mobility associated with compliant substrates has also been shown to influence grasping strategies (Nekaris, 2005; Siemers et al., 2007; Scheumann et al., 2011; Toussaint et al., 2013, 2015; Peckre L., Lowie A., Wall C., Pouydebat E. \& Fabre A-C., unpublished observations). Studies such as this one on captive individuals allow the effect of food properties to be distinguished better from the effects of other environmental variables.

\section{Conclusion}

Importantly, our results indicate that even though captive strepsirrhines do not present variability in their hand-grip types (sole whole-hand power grip), they are able to adjust their grasping strategy depending on the properties of the food. When there is a need for more precision (i.e. to grasp small 
items), strepsirrhines use the mouth. Moreover, the grasping strategies adopted to grasp big items differed depending on the consistency of the food, revealing a new and potentially important factor, food consistency, to consider in future research on grasping abilities.

Considering that strepsirrhines are thought to be more representative than anthropoids of early primates, but nevertheless have their own evolutionary history leading to broad diversification of hand morphology and function, looking across a large set of species to identify common grasping patterns is important for the identification of primitive characters in primates (Pouydebat et al., 2008; Fragaszy \& Crast, 2016). Hence, this study provides important insight into comparative approaches to understanding the evolution of the hand grasping of food in primates. Expansion to include additional tetrapod species will allow the observations on primates to be evaluated more broadly from functional and evolutionary perspectives.

\section{ACKNOWLEDGEMENTS}

The authors warmly thank Dr Adam HarstoneRose and an anonymous reviewer for insightful and constructive comments on an earlier version of this paper. We thank the staff of the Duke Lemur Centre, the staff of the Antwerp Zoo and the staff of the Vincennes Zoo, particularly Delphine Roullet, the primate manager, for their assistance during data collection. We thanks Dr Jonathan M.G. Perry and Dr Adam Harstone-Rose for sharing their observations on head-tilting in ruffed lemurs with us. A.-C.F. thanks the Fondation Fyssen and the Marie-Skłodowska Curie fellowship (EU project 655694 - GETAGRIP) for funding. C.E.W. thanks the National Science Foundation for funding (BCS1062239). J.H. acknowledges the financial support of the Research Training Group 1644 Scaling Problems in Statistics funded by the German Research Foundation (DFG). We thank all the staff at the Duke Lemur Centre for all their help with data collection. This is Duke Lemur Centre Publication Number 1417. This paper is based on a contribution to the European Federation for Primatology symposium, 'What an interdisciplinary approach can tell us about the evolution of grasping and manipulation', held on 21-25 August 2017 at the University of Strasbourg in France and organized by Emmanuelle Pouydebat and Ameline Bardo. The proceedings have been collated into a Special Issue of the Biological Journal of the Linnean Society, guest edited by Emmanuelle Pouydebat and Ameline Bardo.

All authors declare no competing interests.

\section{REFERENCES}

Adams DC. 2014. A generalized $K$ statistic for estimating phylogenetic signal from shape and other high-dimensional multivariate data. Systematic Biology 63: 685-697.

Adams DC, Collyer ML, Kaliontzopoulou A. 2018. Geomorph: software for geometric morphometric analyses. $R$ package version 3.0.6. Available at: https://cran.r-project.org/ package $=$ geomorph

Alvarez MD, Saunders DEJ, Vincent JFV, Jeronimidis G. 2000. An engineering method to evaluate the crisp texture of fruit and vegetables. Journal of Texture Studies 31: 457-473.

Arnold C, Matthews LJ, Nunn CL. 2010. The 10kTrees website: a new online resource for primate phylogeny. Evolutionary Anthropology: Issues, News, and Reviews 19: 114-118.

Baayen RH, Davidson DJ, Bates DM. 2008. Mixed-effects modeling with crossed random effects for subjects and items. Journal of Memory and Language 59: 390-412.

Bates D, Mächler M, Bolker B, Walker S. 2015. Fitting linear mixed-effects models using lme4. Journal of Statistical Software 67: 1-48.

Bishop A. 1962. Control of the hand in lower primates. Annals of the New York Academy of Sciences 102: 316-337.

Bishop A. 1964. Use of the hand in lower primates. In: Buettner-Janusch J, ed. Evolutionary and genetic biology of primates. New-York \& London: Academic Press, 135-225.

Blumstein DT. 2006. The multipredator hypothesis and the evolutionary persistence of antipredator behavior. Ethology 112: 209-217.

Brunon A, Bovet D, Bourgeois A, Pouydebat E. 2014. Motivation and manipulation capacities of the blue and yellow macaw and the tufted capuchin: a comparative approach. Behavioural Processes 107: 1-14.

Cartmill M. 1972. Arboreal adaptations and the origin of the order Primates. In: Tuttle RH, ed. The functional and evolutionary biology of primates. New York: Routledge, 97-122.

Cartmill M. 1974a. Rethinking primate origins. Science 184: 436-443.

Cartmill M. 1974b. Pads and claws in arboreal locomotion. In: Farish A, Jenkins JR, eds. Primate locomotion. New-York and London: Academic Press, 45-83.

Cartmill M. 1992. New views on primate origins. Evolutionary Anthropology: Issues, News, and Reviews 1: 105-111.

Castiello U. 2005. The neuroscience of grasping. Nature Reviews. Neuroscience 6: 726-736.

Chalk J, Wright BW, Lucas PW, Schuhmacher KD, Vogel ER, Fragaszy D, Visalberghi E, Izar P, Richmond BG. 2016. Age-related variation in the mechanical properties of foods processed by Sapajus libidinosus. American Journal of Physical Anthropology 159: 199-209.

Chalk-Wilayto J, Ossi-Lupo K, Raguet-Schofield M. 2016. Growing up tough: comparing the effects of food toughness on juvenile feeding in Sapajus libidinosus and Trachypithecus phayrei crepusculus. Journal of Human Evolution 98: 76-89.

Christel M. 1993. Grasping techniques and hand preferences in Hominoidea. In: Preuschoft H, Chivers DJ, eds. Hands of primates. Wien: Springer, 91-108. 
Christel M, Fragaszy D. 2000. Manual function in Cebus apella. Digital mobility, preshaping, and endurance in repetitive grasping. International Journal of Primatology 21: 697-719.

Curtis VA. 2014. Infection-avoidance behaviour in humans and other animals. Trends in Immunology 35: 457-464.

Cutkosky MR. 1989. On grasp choice, grasp models, and the design of hands for manufacturing tasks. IEEE Transactions on Robotics and Automation 5: 269-279.

Cutkosky MR, Howe RD. 1990. Human grasp choice and robotic grasp analysis. In: Cutkosky MR, Howe RD, eds. Dextrous robot hands. New York: Springer, 5-31.

Dodson DL, Stafford D, Forsythe C, Seltzer CP, Ward JP. 1992. Laterality in quadrupedal and bipedal prosimians: reach and whole-body turn in the mouse lemur (Microcebus murinus) and the galago (Galago moholi). American Journal of Primatology 26: 191-202.

Dumont ER, Herrel A. 2003. The effects of gape angle and bite point on bite force in bats. The Journal of Experimental Biology 206: 2117-2123.

Elliott JM, Connolly KJ. 1984. A classification of manipulative hand movements. Developmental Medicine and Child Neurology 26: 283-296.

Fragaszy DM, Crast J. 2016. Functions of the hand in primates. In: Kivell TL, Lemelin P, Richmond BG, Schmitt D, eds. The evolution of the primate hand. New York: Springer New York, 313-344.

Fulton LV, Mendez FA, Bastian ND, Musal RM. 2012. Confusion between odds and probability, a pandemic? Journal of Statistics Education 20: 1-15.

Gebo DL. 2014. Primate comparative anatomy. Baltimore: Johns Hopkins University Press.

Gould L, Sauther ML. 2007. Anti-predator strategies in a diurnal prosimian, the ring-tailed lemur (Lemur catta), at the Beza Mahafaly Special Reserve, Madagascar. In: Gursky SL, Nekaris AI, eds. Primate anti-predator strategies. Boston: Springer, 275-288.

Hadfield JD. 2010. MCMC methods for multi-response generalized linear mixed models: the MCMCglmm R package. Journal of Statistical Software 33: 1-22.

Hartig F. 2018. DHARMa: residual diagnostics for hierarchical (multi-level/mixed) regression models. $\mathrm{R}$ package version 0.1.6. Available at: https://CRAN.Rproject. org/package=DHARMa

Hartstone-Rose A, Parkinson JA, Criste T, Perry JMG. 2015. Comparing apples and oranges-the influence of food mechanical properties on ingestive bite sizes in lemurs. American Journal of Physical Anthropology 157: 513-518.

Hopkins WD, Cantalupo C, Wesley MJ, Hostetter AB, Pilcher DL. 2002. Grip morphology and hand use in chimpanzees (Pan troglodytes): evidence of a left hemisphere specialization in motor skill. Journal of Experimental Psychology. General 131: 412-423.

Jolly A. 1964. Prosimians' manipulation of simple object problems. Animal Behaviour 12: 560-570.

Jones-Engel L, Bard K. 1996. Precision grips in young chimpanzees. American Journal of Primatology 39: 1-15.
Karl JM, Whishaw IQ. 2013. Different evolutionary origins for the reach and the grasp: an explanation for dual visuomotor channels in primate parietofrontal cortex. Frontiers in Neurology 4: 208.

Kassambara A, Mundt F. 2017. Factoextra: extract and visualize the results of multivariate data analyses. $\mathrm{R}$ package version 1.0.5. Available at: https:/CRAN.Rproject.org/ package $=$ factoextra

Lhota S, Jůnek T, Bartoš L. 2009. Patterns and laterality of hand use in free-ranging aye-ayes (Daubentonia madagascariensis) and a comparison with captive studies. Journal of Ethology 27: 419-428.

Macfarlane NBW, Graziano MSA. 2009. Diversity of grip in Macaca mulatta. Experimental Brain Research 197: 255-268.

Marzke MW, Marchant LF, McGrew WC, Reece SP. 2015. Grips and hand movements of chimpanzees during feeding in Mahale Mountains National Park, Tanzania. American Journal of Physical Anthropology 156: 317-326.

Marzke MW, Marzke RF. 2000. Evolution of the human hand: approaches to acquiring, analysing and interpreting the anatomical evidence. Journal of Anatomy 197: 121-140.

Milliken GW, Stafford DK, Dodson DL, Pinger CD, Ward JP. 1991. Analyses of feeding lateralization in the small-eared bushbaby (Otolemur garnettii): a comparison with the ring-tailed lemur (Lemur catta). Journal of Comparative Psychology 105: 274-285.

Napier JR. 1956. The prehensile movements of the human hand. The Journal of Bone and Joint Surgery. British Volume 38-B: 902-913.

Napier JR. 1960. Studies of the hands of living primates. Proceedings of the Zoological Society of London 134: 647-657.

Nekaris KAI. 2005. Foraging behaviour of the slender loris (Loris lydekkerianus lydekkerianus): implications for theories of primate origins. Journal of Human Evolution 49: $289-300$.

Nelson EL, O’Karma JM, Ruperti FS, Novak MA. 2009. Laterality in semi-free-ranging black and white ruffed lemurs (Varecia variegata variegata): head-tilt correlates with hand use during feeding. American Journal of Primatology 71: 1032-1040.

Peckre L, Fabre AC, Wall CE, Brewer D, Ehmke E, Haring D, Shaw E, Welser K, Pouydebat E. 2016. Holding-on: co-evolution between infant carrying and grasping behaviour in strepsirrhines. Scientific Reports 6: 37729.

Perry JM, Hartstone-Rose A, Wall CE. 2011. The jaw adductors of strepsirrhines in relation to body size, diet, and ingested food size. Anatomical Record 294: 712-728.

Petter JJ. 1962. Ecological and behavioral studies of Madagascar lemurs in the field. Annals of the New York Academy of Sciences 102: 267-281.

Pouydebat E, Fragaszy D, Kivell TL. 2014. Grasping in primates: for feeding, moving and human specificities. Bulletin et Mémoires de la Société D’anthropologie de Paris 26: 129-133. 
Pouydebat E, Gorce P, Coppens Y, Bels V. 2009. Biomechanical study of grasping according to the volume of the object: human versus non-human primates. Journal of Biomechanics 42: 266-272.

Pouydebat E, Laurin M, Gorce P, Bels V. 2008. Evolution of grasping among anthropoids. Journal of Evolutionary Biology 21: 1732-1743.

Pouydebat E, Reghem E, Borel A, Gorce P. 2011. Diversity of grip in adults and young humans and chimpanzees (Pan troglodytes). Behavioural Brain Research 218: 21-28.

Pouydebat E, Reghem E, Gorce P, Bels V. 2010. Influence of the task on hand preference: individual differences among gorillas (Gorilla gorilla gorilla). Folia Primatologica; International Journal of Primatology 81: 273-281.

R Core Team. 2016. $R$ : a language and environment for statistical computing. Vienna,: R Foundation for Statistical Computing.

Rasmussen DT. 1990. Primate origins: lessons from a neotropical marsupial. American Journal of Primatology 22: 263-277.

Ravosa MJ, Dagosto M. 2007. Primate origins: adaptations and evolution. New York: Springer.

Reghem E, Byron C, Bels V, Pouydebat E. 2012. Hand posture in the grey mouse lemur during arboreal locomotion on narrow branches: manual grasping during locomotion in Microcebus murinus. Journal of Zoology 288: 76-81.

Reghem E, Chèze L, Coppens Y, Pouydebat E. 2013. Unconstrained 3D-kinematics of prehension in five primates: lemur, capuchin, gorilla, chimpanzee, human. Journal of Human Evolution 65: 303-312.

Reghem E, Tia B, Bels V, Pouydebat E. 2011. Food prehension and manipulation in Microcebus murinus (Prosimii, Cheirogaleidae). Folia Primatologica; International Journal of Primatology 82: 177-188.

Ross CF, Martin RD. 2007. The role of vision in the origin and evolution of primates. In: Preuss TM, Kaas J, eds. Evolution of nervous systems. Vol. 4: the evolution of primate nervous systems. Oxford: Elsevier, 59-78.

Roy AC, Paulignan Y, Meunier M, Boussaoud D. 2002. Prehension movements in the macaque monkey: effects of object size and location. Journal of Neurophysiology 88: 1491-1499.

Santello M, Flanders M, Soechting JF. 2002. Patterns of hand motion during grasping and the influence of sensory guidance. The Journal of Neuroscience 22: 1426-1435.

Santos LR, Mahajan N, Barnes JL. 2005. How prosimian primates represent tools: experiments with two lemur species
(Eulemur fulvus and Lemur catta). Journal of Comparative Psychology 119: 394-403.

Scheumann M, Joly-Radko M, Leliveld L, Zimmermann E. 2011. Does body posture influence hand preference in an ancestral primate model? BMC Evolutionary Biology 11: 52.

Schöneich S. 1993. Hand usage in the ring tailed lemur (Lemur catta Linnaeus 1758) when solving manipulative tasks. In: Preuschoft H, Chivers DJ, eds. Hands of primates. Wien: Springer, 7-20.

Siemers BM, Goerlitz HR, Robsomanitrandrasana E, Piep M, Ramanamanjato J-B, Rakotondravony $D$, Ramilijaona O, Ganzhorn JU. 2007. Sensory basis of food detection in wild Microcebus murinus. International Journal of Primatology 28: 291.

Sussman RW, Rasmussen DT, Raven PH. 2013. Rethinking primate origins again. American Journal of Primatology 75: 95-106.

Sustaita D, Pouydebat E, Manzano A, Abdala V, Hertel F, Herrel A. 2013. Getting a grip on tetrapod grasping: form, function, and evolution. Biological Reviews of the Cambridge Philosophical Society 88: 380-405.

Taniguchi H. 2015. How the physical properties of food influence its selection by infant Japanese macaques inhabiting a snow-covered area. American Journal of Primatology 77: 285-295.

Torigoe T. 1985. Comparison of object manipulation among 74 species of non-human primates. Primates 26: 182-194.

Toussaint S, Herrel A, Ross CF, Aujard F, Pouydebat E. 2015. Substrate diameter and orientation in the context of food type in the gray mouse lemur, Microcebus murinus: implications for the origins of grasping in primates. International Journal of Primatology 36: 583-604.

Toussaint S, Reghem E, Chotard H, Herrel A. 2013. Food acquisition on arboreal substrates by the grey mouse lemur: implication for primate grasping evolution: hand use during food acquisition in Microcebus murinus. Journal of Zoology 291: 235-242.

Ward JP, Milliken GW, Dodson DL, Stafford DK, Wallace M. 1990. Handedness as a function of sex and age in a large population of Lemur. Journal of Comparative Psychology 104: 167-173.

Wood FJ. 1916. Arboreal man. Longmans, eds.

Zehr SM, Roach RG, Haring D, Taylor J, Cameron FH, Yoder AD. 2014. Life history profiles for 27 strepsirrhine primate taxa generated using captive data from the Duke Lemur Center. Scientific Data 1: 140019.

\section{SUPPORTING INFORMATION}

Additional Supporting Information may be found in the online version of this article at the publisher's web-site:

Appendix S1. Sample size per species.

Appendix S2. List of food items included in the diet for both consistency categories.

Appendix S3. Model selection procedure.

Appendix S4. Goodness-of-fit plots for the full model M5.0.

Appendix S5. Goodness-of-fit plots for the full model UM4.0. 